\title{
Comportamento de busca e uso da informação: um estudo com alunos participantes de empresas juniores
}

Marco Antonio Carvalho Brum

\begin{abstract}
Mestre em Ciência da Informação -Escola de Ciência da Informação - Universidade Federal de Minas Gerais
\end{abstract}

Ricardo Rodrigues Barbos

\begin{abstract}
Professor Titular da Escola de Ciência da Informação-Universidade Federal de Minas Gerais
\end{abstract}

Este trabalho analisa o comportamento informacional de participantes de empresas juniores no Brasil. Foram analisadas fontes de informação em termos de sua frequência, relevância e confiabilidade. Os resultados indicaram que as fontes mais acessadas e mais relevantes são as pessoais, seja via internet ou em contatos diretos por uma simples conversa. Livros e professores foram considerados as fontes mais confiáveis. Os alunos responderam que usam as fontes de informação determinadas, principalmente para o aprendizado e para compartilhar com outras pessoas.

Palavras-chave: Comportamento informacional; Fontes de informação; Empresa júnior.

\section{Search and use information behavior: a study with member participants of junior enterprises}

This work analyzes the information behavior of member of junior enterprises in Brazil. Sources were analyzed in terms of their frequency, relevance and reliability. Moreover, it was investigated the usefulness of these sources for different goals. The results show that personal sources are more often accessed and more relevant, either through the Internet or in direct contacts for a simple conversation. The most reliable sources for them are the books and the teachers. The students answered 
that they use predetermined information sources mainly for learning and sharing information with other people.

Keywords: Information behavior; Information sources; Junior enterprise.

Recebido em 21.10.2008 Aceito em 24.07.2009

\section{Introdução}

O ambiente que se descortina dentro da sociedade da informação é composto por pessoas e organizações que necessitam, buscam, disseminam e usam a informação sem se preocupar com a sistematização desse processo. As organizações se vêem envoltas por quantidades cada vez maiores de dados em seus sistemas computacionais, gerando diariamente enormes volumes de informação sem o seu devido gerenciamento. Para os usuários, esse excesso de informação se torna angustiante, devido ao fato de eles terem acesso e não conseguirem absorvê-la, usá-la para atingir um objetivo ou mesmo para executar alguma tarefa.

Para os indivíduos, de maneira geral, ter consciência sobre a necessidade de informação é algo subjetivo e difícil de ser alcançado. Posteriormente, efetuar a procura por essa informação depende da acessibilidade e da relevância das fontes de informação, as quais são selecionadas conforme as escolhas subjetivas do usuário. A confiança e a facilidade de acesso às fontes são fatores que auxiliam na busca pela informação. O uso da informação, dentro da dinâmica comportamental, está relacionado à transformação do usuário da informação em agente ativo, de acordo com suas necessidades; à qualidade, acessibilidade e confiança nas fontes disponíveis e escolhidas.

O presente trabalho tem o propósito de estudar como os alunos participantes de empresas juniores $(E J)^{1}$, distribuídas pelo Brasil, se comportam diante de um número previamente escolhido de fontes de informação, disseminadas por vários meios formais ou informais, pessoais ou impessoais (CHOO, 1994) e também eletrônicas e não-eletrônicas (PEREIRA, 2006). De acordo com o Conceito nacional de Empresa Júnior (BRASIL JÚNIOR..., 2006), as EJ são organizações sem finalidades econômicas, mas com fins educacionais. Elas têm seu próprio CNPJ, garantindo assim sua atividade como sendo juridicamente válida ao prestar serviços para as micro e pequenas empresas, por exemplo.

De forma geral, a pesquisa pretende fazer um levantamento e analisar o comportamento informacional dos alunos participantes das empresas juniores, com foco em como eles buscam e usam a informação para executar tarefas específicas na empresa júnior. De maneira mais direcionada, pretende-se:

\footnotetext{
'Será utilizada nesse trabalho a sigla EJ em substituição à expressão "Empresa Júnior".
} 
1. Determinar o perfil dos participantes de EJ segundo o gênero, a idade, a universidade/ faculdade onde estudam, o curso de graduação no qual estão matriculados, o tempo de empresa júnior, o papel dentro da EJ, o tempo dedicado à EJ, e os principais tipos de clientes;

2. Analisar as diversas fontes de informação utilizadas pelos participantes das EJ com base nos critérios de frequência de uso;

3. Avaliar a relevância das fontes de informação por parte dos alunos participantes das EJ;

4. Avaliar qual o grau de confiabilidade das fontes de informação buscadas pelos alunos participantes;

5. Analisar como os alunos participantes usam da informação para executar suas tarefas nas $E J$, com base na frequência de uso e na importância das fontes.

\section{Comportamento de busca e uso da informação}

Para mudar o seu estado de conhecimento e "preencher" as lacunas cognitivas, o indivíduo parte em busca da informação. O modelo apresentado por Ellis (1989) e Ellis, Cox e Hall (1993) é também apresentado no artigo de Wilson (1999), Models in Information Behavior Research e, através do estudo com cientistas sociais, médicos pesquisadores e químicos, aponta padrões de comportamento em que a busca é determinada por oito características: iniciação, encadeamento, browsing (procura), diferenciação, monitoramento, extração, verificação e finalização.

A iniciação são atividades características iniciais da busca por informação. Encadeamento é uma seqüência ou cadeias de referenciais que se conectam entre si. Browsing ou procura é uma busca semidirecionada em um local de possível interesse, sem compromisso. Já na diferenciação há uma consciência das diferenças de natureza e qualidade do material pesquisado nas diferentes fontes de informação. 0 monitoramento serve de manutenção da qualidade do desenvolvimento em um campo, através do acompanhamento das fontes de informação. Na extração, retira-se o que é material de interesse para algum trabalho específico. Enquanto que a verificação são as atividades associadas à checagem da precisão da informação. E, por último, a finalização, que é tratada como as atividades características de busca de informação no final de algum projeto, preparando para executar alguma tarefa ou em busca de algum objetivo.

A busca por determinada informação é dependente também da qualidade da fonte de informação que irá determinar o padrão de busca e a facilidade de se acessá-la. Wilson (2000) apresenta o conceito de comportamento de busca como sendo aquele com conseqüências para satisfazer a uma necessidade ou atingir um objetivo previamente planejado. 
Para o autor supracitado, há dois conceitos que devem ser entendidos, pois eles são sutis e se complementam dentro do comportamento de busca da informação. São eles: information seeking behavior e information searching behavior. Na tradução para o português, seriam quase que sinônimos, portanto viu-se a necessidade de não traduzir, mas explicar o seu significado.

Wilson (2000) propõe que information seeking behavior

[...] seja a busca intencional pela informação como conseqüência de uma necessidade de cumprir um objetivo. Ao longo da busca, o indivíduo pode interagir com os sistemas de informação manual (como um jornal impresso ou uma biblioteca), ou com sistemas computacionais (como a World Wide Web) (WILSON, 2000, p. 49, tradução nossa).

Complementando o conceito de comportamento de busca informacional, esse autor define information searching behavior

[...] como o micro-nível do comportamento empregado pelo pesquisador em interação com todos os tipos de sistemas de informação. Consiste de todas as interações com o sistema, se ao nível da interação homem-computador (por exemplo, uso do mouse e cliques nos links) ou ao nível intelectual (por exemplo, ao adotar a estratégia booleana de busca ou ao determinar o critério de escolha de quais dos dois livros selecionados de lugares adjacentes na prateleira numa biblioteca é mais útil), que também envolverá atividades mentais como julgar a relevância de dados ou informações recuperadas (WILSON, 2000, p. 49, tradução nossa).

Segundo o Online Etymology Dictionary ${ }^{2}$ (HARPER, 2001), a palavra search vem do latim circare, pela palavra em francês antigo cerchier. A origem da palavra seek, entretanto, consultada no The Free Dictionary by Farlex ${ }^{3}$ (FARLEX INC., 2004), é proveniente do Inglês Médio (Middle English) sechen, seken, vindo do Inglês Antigo secan.

As duas palavras são sinônimas, mas apresentam variações sutis em seus significados, que influenciaram a decisão de Wilson (2000), nas citações acima, de separar o searching behavior do seeking behavior. 0 comportamento informacional de seeking é a tentativa de se obter a informação ou a procura por informação, já o comportamento informacional de searching está mais próximo do ato de examinar, investigar alguma informação perdida; é a atividade de explorar a informação mais de perto, utilizando os sistemas computacionais, conforme observado por Wilson (2000).

O modelo do processo de busca da informação foi estudado e discutido por Kuhlthau (1991) na perspectiva do usuário. Os estágios

\footnotetext{
${ }^{2}$ Disponível em: <http://www.etymonline.com>. Acesso em: 10 ago. 2009.

${ }^{3}$ Disponível em: <http://www.thefreedictionary.com>. Acesso em: 10 ago. 2009.
} 
apresentados e discutidos pela pesquisadora em seu modelo são: Iniciação, Seleção, Exploração, Formulação, Coleção e Apresentação. Esse modelo, segundo Wilson (1999), é um complemento dos estudos de Ellis (1989).

A Iniciação é uma fase do processo que pode ser caracterizada por sentimentos de incerteza, com pensamentos gerais sobre os problemas a serem resolvidos.

A Seleção é um estágio de reconhecimento da tarefa a ser desempenhada mais a bagagem informacional e, portanto, da consciência da necessidade informacional. É uma fase de otimismo.

$\mathrm{Na}$ fase da Exploração, os sentimentos de incerteza, confusão e dúvida perduram, mas há estratégias e ações que podem fazer com que melhorem os sentimentos anteriores como, por exemplo, listar os fatos pertinentes e refletir sobre algumas idéias.

A Formulação é a fase da clareza e enfoca um tópico específico da tarefa a ser solucionada. Há uma mudança nos sentimentos, com aumento da segurança e maior senso de clareza.

Na Coleção, há um levantamento da informação relevante, baseado no foco de pesquisa. É um estágio no processo em que a interação entre o usuário e o sistema de informação funciona mais efetivamente.

A Apresentação é caracterizada como a fase do senso de satisfação; se a busca foi bem ou de desapontamento, se não houve sucesso no processo de busca em torno de um objetivo determinado.

Após o devido reconhecimento da ausência de informação, a busca pela informação é definida, segundo Case (2002), estritamente em termos do comportamento ativo e intencional, que limita sua aplicabilidade na dimensão extensa de pesquisa, atualmente conduzida pelo uso da informação dos indivíduos.

Na seqüência do comportamento informacional, o uso da informação é, segundo Choo (2006), o conjunto entre seleção e processamento da informação. Ele se configura como uma visível mudança no estado do conhecimento e, conseqüentemente, na capacidade de o indivíduo utilizar a informação para executar alguma ação efetiva, "responder a uma pergunta, resolver algum problema, tomar uma decisão ou entender uma situação" (CHOO, 2003, p. 107).

Para entender melhor o uso da informação pelos indivíduos, Taylor (1991) propõe oito categorias baseadas na relevância que os seres dão à informação. São elas: o esclarecimento, a compreensão do problema, a parte instrumental, a questão factual, a confirmação, a projeção de um acontecimento, a motivação e as questões pessoais e políticas. Taylor (1991) aponta que os trabalhos de Dervin e Nilan (1986) e colegas foram importantes referências para esta categorização.

Todas as categorias apresentadas se sobrepõem e uma não exclui a outra. Ao contrário, elas se complementam e precisam umas das outras para caracterizar a importância identificada pelos indivíduos ao usar a informação. Sem esquecer que o contexto ou ambiente onde a informação é utilizada pode afetar o resultado do comportamento informacional como 
um todo, assim como a variedade de fontes de informação e os tipos diferentes de usuários.

No esclarecimento, a informação é usada para desenvolver um contexto adequado ou para criar sentido a uma situação. A informação é trabalhada para responder questões sobre a organização. Há situações similares? Quais são elas?

Para o entendimento do problema, a informação é usada em um caminho mais específico do que na categoria anterior. Ela é usada para desenvolver uma melhor compreensão de um problema particular. Dervin chama de capacidade de decidir, preparar e planejar.

Na parte instrumental descobre-se o que fazer e como fazer alguma coisa. As instruções são uma forma comum de informação instrumental. Para Dervin, é o desenvolvimento de habilidades para ler e interpretar as instruções.

Na questão factual a informação é usada para determinar os fatos de um fenômeno ou evento, para descrever a realidade. $O$ uso da informação factual depende de dois fatores: a) a qualidade e atualidade da informação (o quão ela representa fielmente a realidade); e, relacionada com o fator acima, b) a percepção da qualidade por parte do usuário.

A necessidade de confirmar um trecho ou pedaço da informação é um tipo de uso chamado por Taylor de confirmação. Ela envolve a busca por uma segunda opinião. Se essa nova opinião não se confirmar, então o indivíduo pode reformular o problema para tentar reinterpretar a informação ou escolher outra fonte para confiar. É uma atitude comumente verificada em gerentes.

O uso projetivo da informação serve para verificar o que irá acontecer no futuro. É utilizada tipicamente para estimativas, probabilidades e previsões, não para situações pessoais, mas em termos mais gerais e amplos.

A categoria motivacional usa a informação para manter as pessoas em uma atividade contínua, através do envolvimento interpessoal em torno de um objetivo.

$\mathrm{E}$, por último, a informação usada para fins pessoais e políticos melhora o envolvimento e o desenvolvimento de relacionamentos e aumenta seu status e sua reputação diante de situações diárias e/ou do trabalho.

O uso adequado da informação é dependente da qualidade e da relevância das fontes de informação identificadas pelos usuários da informação. O uso da informação "encontrada depende também de como o indivíduo avalia a relevância cognitiva e emocional da informação recebida e atributos objetivos capazes de determinar a pertinência da informação a uma determinada situação problemática" (CHOO, 2003).

As seções a seguir tratam dos diferentes tipos e categorias de fontes de informação apresentadas por pesquisadores da área. 


\section{Fontes de informação}

Segundo Auster e Choo (1993), as fontes de informação nas organizações podem ser externas ou internas, pessoais ou impessoais. Elas se dividem em quatro categorias: pessoais externas, pessoais internas, impessoais externas e impessoais internas.

Em um estudo sobre as "fontes de informação sobre o ambiente organizacional externo", Barbosa (2002) organizou 17 fontes de informação baseadas nessas quatro categorias citadas e analisou-as, junto a 91 estudantes de pós-graduação que atuam em diversas empresas de vários portes, em função de seu grau de relevância, de freqüência e de confiabilidade. Os dados indicaram que as fontes documentais externas (jornais, revistas, rádio e televisão) são mais frequentemente acessadas, no entanto, essas fontes foram consideradas pouco confiáveis. Já as publicações governamentais foram consideradas muito confiáveis, embora pouco usadas e pouco relevantes. As outras fontes externas (associações empresariais, congressos, feiras e viagens) apresentaram pouca utilização, relevância e confiabilidade. A fonte pessoal interna mais utilizada foram os colegas do mesmo nível hierárquico. Os superiores em hierarquia são considerados fontes de grande confiabilidade. As fontes pessoais externas (clientes, concorrentes, parceiros e associados) foram pouco acessadas. Os dados encontrados revelaram que as fontes pessoais de informação são insubstituíveis, mesmo com o grande aumento de acesso às fontes eletrônicas de informação.

A TAB. 1 resume melhor as fontes de informação organizacionais (AUSTER; CHOO, 1994).

TABELA 1 - Fontes de Informação Organizacional

\begin{tabular}{|c|c|c|}
\hline & PESSOAIS & IMPESSOAIS \\
\hline EXTERNAS & $\begin{array}{l}\text { - Clientes } \\
\text { - Concorrentes } \\
\text { - Contatos comerciais/ } \\
\text { profissionais } \\
\text { - Funcionários de órgãos } \\
\text { governamentais }\end{array}$ & $\begin{array}{l}\text { - Jornais, periódicos } \\
\text { - Publicações governamentais } \\
\text { - Rádio, televisão } \\
\text { - Associações comerciais e industriais } \\
\text { - Conferências, viagens }\end{array}$ \\
\hline INTERNAS & $\begin{array}{l}\text { - Superiores e subordinados } \\
\text { hierárquicos } \\
\text { - Equipe de funcionários }\end{array}$ & $\begin{array}{l}\text { - Memorandos e circulares internos } \\
\text { - Relatórios e estudos internos } \\
\text { - Biblioteca da organização } \\
\text { - Serviços de informação eletrônica }\end{array}$ \\
\hline
\end{tabular}

Fonte: Adaptado de AUSTER; CHOO, 1994.

É importante atentar para o fato de que, na época, as fontes de informação, utilizando-se como suporte a Internet, eram pouco ou nada utilizadas. 
Eles classificaram as fontes informacionais em pessoais e externas, impessoais e externas, pessoais e internas, e impessoais e internas.

Em um trabalho recente, Barbosa (2006) investigou o uso de fontes de informação em empresas de pequeno e grande porte, e sua importância como recursos para a inteligência competitiva. A metodologia utilizada se assemelhava às empregadas por Auster e Choo (1994) e Barbosa (2002), em que se analisou e avaliou a freqüência, a relevância e a confiabilidade das fontes de informação, critérios utilizados na presente pesquisa com os alunos participantes de EJ.

Outro estudo, de Bastos e Barbosa (2005), analisou 92 executivos de empresas de tecnologia da informação. Os resultados indicaram um predomínio do uso de fontes externas para se obter informações do ambiente externo, tendo sido consideradas mais relevantes e confiáveis, e utilizadas com maior freqüência.

Para Burke (1996), há três tipos de fontes de informação a serem consideradas para empresas prestadoras de serviços: fontes interpessoais, publicações oficiais da empresa e fontes informais. Em seu estudo, ele avalia as fontes apresentadas, a quantidade de informação recebida dessas fontes, quais são as preferidas e o valor de cada uma delas para o desempenho no trabalho. Ele identificou, em seu trabalho, que as fontes interpessoais e informais são preferencialmente mais acessadas em relação às oficiais.

Em outro estudo, Burke (2001) investigou a relação do gênero com as fontes de informação, tendo identificado que as fontes preferidas das mulheres são as provenientes das relações interpessoais, e que elas são as que mais recebem informações dos três grandes tipos identificados por Burke (1996).

Segundo Norman (1997, p. 125), as fontes de informação eletrônicas cresceram significativamente em acesso nas bibliotecas. Ele lista abaixo os principais tipos de fontes eletrônicas nas bibliotecas: "CDROM, publicações na internet, banco de dados online, fitas magnéticas; e vários outros caminhos de entrada disponíveis".

Sua produção e seu uso estão sendo largamente empregados em outros ambientes, sendo que as publicações na Internet aumentaram em grande escala desde o estudo de Norman (1997). São fontes que podem ser consideradas como provenientes dela: World Wide Web (WWW), Gopher $^{4}$, telnet ${ }^{5}$, file transfer protocol (FTP) ${ }^{6}$ e e-mail. Ainda são fontes de informação na internet: grupos de discussão, jornais e newsletters online, e-books (NORMAN, 1997). Muito se evoluiu depois dos estudos de Norman, conforme se observa a seguir.

\footnotetext{
${ }^{4}$ Gopher é um protocolo de redes de computadores que foi desenhado para indexar repositórios, atuando assim como um mecanismo de busca de documentos na Internet. Foi especificado em 1991 por Paul Lindner e Mark McCahill, da Universidade de Minesota (WIKIPEDIA, 2009).

${ }^{5}$ Telnet é um protocolo cliente-servidor de comunicações usado para permitir a comunicação entre computadores ligados numa rede (exemplos: rede local / LAN, Internet). Telnet é um protocolo de login remoto (WIKIPEDIA, 2009).

6 FTP significa File Transfer Protocol (Protocolo de Transferência de Arquivos), e é uma forma bastante rápida e versátil de transferir arquivos (também conhecidos como ficheiros), sendo uma das mais usadas na Internet (WIKIPEDIA, 2009).
} 
Para Pereira (2006), as fontes podem ser classificadas utilizando-se de três critérios, conforme mostra o gráfico abaixo. Nele observa-se que, além do que foi proposto por Auster e Choo (1994) e Barbosa (2002), com suas variáveis pessoais e impessoais, internas e externas, há mais uma variável componente que são os tipos de fontes eletrônicas e nãoeletrônicas. A figura 4 representa os tipos de fontes de informação usadas por consultores de empresas investigados pelo pesquisador. As fontes escolhidas foram categorizadas segundo três critérios, e cada um deles possui uma variável oposta (PEREIRA, 2006, p. 79-80).

a- Com relação à origem (com relação à empresa ou negócio de consultoria): fontes internas ou externas;

b- Com relação ao relacionamento / proximidade: fontes pessoais ou impessoais (sendo fonte pessoal a que proporciona troca de informações entre o consultor e outra pessoa, e fonte impessoal aquela utilizada pelo consultor para a busca de informações relevantes, podendo ser esta fonte, na maioria das vezes, de caráter documental ou formal); e

c- Com relação à mídia: fontes eletrônicas (informações obtidas através da Internet, de mídia eletrônica, CD-ROMs ou disquetes, bases de dados on-line, etc.) e não-eletrônicas (informações em papel).

Para a pesquisa de Pereira (2006), foram identificadas e analisadas 30 fontes de informação mais utilizadas por consultores empresariais em suas atividades profissionais. Os resultados apontaram para um maior uso das fontes eletrônicas, mas as fontes pessoais foram consideradas as mais relevantes e confiáveis. Para os consultores, as fontes são utilizadas prioritariamente para a tomada de decisões em seu ambiente de trabalho.

A seção seguinte indica a tendência de uso das fontes de informação consideradas por Pereira (2006) como eletrônicas; em função disso, alguns autores já desenvolvem pesquisas sobre o assunto. Trabalha-se a seguir com o termo fontes de informação na Internet, por entender que as fontes eletrônicas são provenientes, em sua maioria, da grande rede mundial.

Com o grande aumento de acesso à internet, os usuários da informação estão utilizando-a como uma das principais fontes para adquirir informação. Para Tomaél et al (2001, p. 3) ela é o "resultado da convergência das tecnologias da computação e da comunicação; a Internet representa uma verdadeira revolução nos métodos de geração, armazenagem, processamento e transmissão da informação".

A Internet, como fonte de informação, pode ser dividida em vários setores, ou seja, há muitas formas de se ter acesso à informação pela grande rede, sendo elas: listas de discussão, correio eletrônico (e-mail), informativos via correio eletrônico (newsletter), informativos comerciais via correio eletrônico (e-mail marketing), salas de bate-papo virtual (chat), mensageiros instantâneos (instant messengers), sítios de busca ou ferramentas de busca, intranets, extranets e os próprios sítios (sites) disponíveis na web. 
Não se pode negar que a Internet ocupa um espaço importante nos processos informacionais e, atualmente, é um fator determinante no comportamento informacional do indivíduo em termos de necessidade, busca e uso da informação. Situação comprovada por estudos como o de Choo, Detlor e Turnbull (1999), visto que eles pesquisam os comportamentos de busca baseados na web por trinta e quatro diferentes tipos de usuários, de sete empresas e de três setores diferentes.

A seção seguinte é um complemento teórico às características fundamentais do objeto de estudo e seu ambiente organizacional. As EJ são consideradas como estímulo ao empreendedorismo, pelo fato de proporcionar aos seus participantes a oportunidade de se envolverem com a criação de seu próprio negócio.

\section{0 empreendedorismo e a empresa júnior}

Com o objetivo de apresentar e aprofundar os estudos sobre as empresas juniores no Brasil, é importante desenvolver uma breve fundamentação teórica com os principais autores da área e que dão suporte à presente pesquisa.

Segundo David (2004), os economistas de séculos atrás, como Richard Cantillon, Jean-Baptist Say, Adam Smith e, mais recentemente, Joseph Alois Schumpeter, associaram o empreendedor à inovação e ao desenvolvimento econômico.

Filion (1999), pesquisador canadense que estuda o empreendedorismo, propõe uma definição de empreendedor:

O empreendedor é uma pessoa criativa, marcada pela capacidade de estabelecer e atingir objetivos e que mantém um alto nível de consciência do ambiente em que vive usandoa para detectar oportunidades de negócios. Um empreendedor que continua a aprender a respeito de possíveis oportunidades de negócios e a tomar decisões moderadamente arriscadas que objetivam a inovação, continuará a desempenhar um papel empreendedor. Resumindo nos aspectos essenciais: 'um empreendedor é uma pessoa que imagina, desenvolve e realiza visões' (FILION, 1999, p. 19).

O empreendedor é, portanto, em consonância com o assunto pesquisado, um usuário de informação que tem um comportamento informacional, ou seja, de acordo com Filion (1999), ele imagina, desenvolve e realiza, inferindo-se, portanto, uma correlação entre a necessidade, a busca e o uso da informação.

O empreendedor, para Schumpeter (1954) apud Filion (1999), no início do século $X X$, era alguém associado à inovação e que tinha uma percepção das novas oportunidades de negócios diferenciada, e, mais importante, que sabia como criar novas formas de empregar ou usar os recursos. Esse tipo de pensamento se encaixa com os paradigmas atuais, no sentido de que o novo empreendedor deve saber como criar novas formas de usar a informação a partir dos novos recursos informacionais. 
Assim, empresas são criadas por iniciativas de universidades que fomentam incubadoras para preparar futuros investidores em suas spinoffs, a partir do ambiente universitário. Sem aprofundar no assunto, para Blais et al (1997), spin-off é uma empresa formada por um ou mais empregados de uma grande ou pequena organização, que se uniram para desenvolver um mercado ou um produto relacionado às atividades de uma empresa incubadora, mas sem estar sob o controle dela.

No caso apresentado por Lemos, Grizendi e Lotufo (2005), a INOVA, incubadora da UNICAMP (Universidade de Campinas), é a incentivadora de atividades acadêmicas e pré-incubadora de promissores e futuros negócios, desenvolvida em outros ambientes dentro da universidade. Ela inclusive estimula a integração com as 16 EJ da instituição para intensificarem os processos de pré-incubação. Essa iniciativa tem melhorado e fomentado, de acordo com Lemos, Grizendi e Lotufo (2005), o crescimento das EJ e dos interesses dos alunos em torno do empreendedorismo.

Fato que vai de encontro à idéia de que o comportamento empreendedor está relacionado ao ambiente propício para se empreender, conforme a cultura, as necessidades e os hábitos de uma região (FILION, 1999), de uma comunidade, ou mesmo de uma organização. Este último é chamado de intra-empreendedorismo, que pode ser definido pelo seu agente: o intra-empreendedor.

Segundo David (2004), são pessoas que

[...] anseiam por liberdade dentro da organização, são orientados para metas, comprometidos e automotivados, mas também reagem às recompensas e ao reconhecimento da empresa. São indivíduos que "põem a mão na massa" e fazem o que deve ser feito. Gostam de riscos moderados, não temem ser demitidos e por isso vêem pouco risco pessoal. $E$, principalmente, fogem do estado estável, detestam as rotinas, pois são criativos e inovadores. Pode-se, resumidamente, caracterizar o intra-empreendedor como uma pessoa que é persistente, trabalha arduamente, é decidida e autoconfiante, orienta-se por seu objetivo e não para obter status ou dinheiro (DAVID, p. 45, 2004).

O trabalho do intra-empreendedor em uma organização se identifica com o aluno participante de EJ, na medida em que este acredita que seu trabalho irá impulsioná-lo para o crescimento profissional.

O intuito dessa seção é indicar a importância do empreendedorismo para o surgimento e a orientação das EJ. Há uma tendência ao crescimento e desenvolvimento do espírito empreendedor por parte de seus alunos participantes.

O Movimento Empresa Júnior se iniciou na França, em 1967, na Escola Superior de Ciências Econômicas e Comerciais de Paris, com o intuito de fundar uma empresa ou associação civil, sem fins lucrativos, em 
que os estudantes de graduação regularmente matriculados em instituições de ensino superior poderiam participar.

No Brasil, o movimento começou em 1988, na Fundação Getúlio Vargas (FGV), e hoje já se estende por mais de 600 empresas juniores, sendo 150 somente em Minas Gerais, segundo a FEJEMG (Federação das Empresas Juniores do Estado de Minas Gerais).

Com a mobilização das federações estaduais, foi criada, em 2003, a Confederação Brasileira de Empresas Juniores, ou "Brasil Júnior", que tem como objetivos organizar, representar e auxiliar no trabalho das 11 federações brasileiras já confederadas a ela.

Este tipo de associação tem como objetivo primário o aprendizado por meio da prática e do exercício da profissão, prestando serviços para entidades e para a sociedade em geral, dependendo da área de atuação. A EJ é supervisionada, na maioria das vezes, por professores do curso de graduação ao qual estão vinculados.

O foco principal de trabalho das EJ são as micro e pequenas empresas (PME), que contratam seus serviços por não poderem investir em consultorias profissionais devido ao seu alto custo.

Há uma troca bastante rica entre as EJ e as PME, no sentido de servirem umas às outras, profissional e academicamente, na formação dos futuros profissionais para o mercado de trabalho, desenvolvendo serviços a custo mais vantajoso para as PME.

Comparativamente às atividades das EJ, no trabalho de Pereira (2006), alguns dados podem ser destinados às atividades de consultoria dos consultores empresariais profissionais, investigadas em diversos setores, mas que podem indicar uma tendência também para os empresários juniores.

Em sua pesquisa, observa-se que:

Mesmo sendo os consultores pesquisados profissionais autônomos ou pertencentes à MPE de consultoria, atendem empresas tanto de micro, pequeno $(80,8 \%)$, médio $(87,5 \%)$ e grande portes $(77,9 \%)$, caracterizando a atividade de consultoria como uma prestação de serviços diferenciada, quando comparada a outras prestações de serviços (PEREIRA, 2006, p. 96).

Essa diferenciação na prestação de serviços também é vista nas atividades das EJ, já que várias delas também são fontes de inovação para o mercado. Algumas trabalham em setores onde o valor agregado está no desenvolvimento de novos produtos, novas fórmulas, etc., conforme Leão (1997), do Jornal da USP, instituição que, a título de exemplo, congrega onze empresas juniores em suas instalações.

Segundo Souza (2002), essas empresas:

[...] constituem um processo que capacita alunos universitários através de desenvolvimento de projetos para clientes do mercado e do gerenciamento de questões 
pertinentes a uma empresa de natureza real, proporcionando uma contribuição diferenciada e oferecendo melhor preparação para o universitário enfrentar as incertezas e necessidades do mercado de trabalho (SOUZA, 2002, p. 100).

Seus participantes, ou propriamente os alunos, para comporem uma EJ, devem estar matriculados na universidade ou faculdade que cede o espaço para seu funcionamento. Estes alunos podem ser considerados estagiários, consultores, membros do conselho ou até mesmo diretores da EJ, dependendo do Estatuto Social da empresa ou da sua relação com a Instituição de Ensino Superior da qual fazem parte.

Assim, como os estágios são exigidos regularmente em alguns cursos de graduação para a formação profissional dos alunos, as EJ são formas efetivas de inseri-los no mercado profissional, além de despertarem neles um interesse empreendedor que pode levá-los a investir na carreira, como proprietários do seu negócio.

Para ilustrar o presente estudo, apresenta-se o caso da formação da empresa júnior Qualitas, da FACAMP (Faculdades de Campinas). Ele foi relatado em um artigo de Graça e Pais (2003), que conta como foi instituída a EJ Qualitas, que tinha como objetivo, ou justificativa para a direção da instituição, a criação de um local onde os estudantes dos cursos de Administração e de Economia pudessem suprir as lacunas entre a teoria da sala de aula e a prática do mercado de trabalho; além de desenvolver suas habilidades técnicas e interpessoais, através dos projetos desenvolvidos. Para dar continuidade ao processo de criação da Qualitas, foram definidos passos a serem realizados: criar a estrutura organizacional; elaborar o estatuto; definir o plano de negócios; apresentar a empresa ao corpo discente; selecionar os consultores; registrar a EJ.

No caso da Qualitas, Graça e Pais (2003) relataram que os alunos fizeram uma pesquisa e trabalharam com os modelos de EJ anteriormente criadas em outras universidades ou faculdades. Os alunos observaram que, em algumas EJ, havia diferenças nas suas estruturas organizacionais. Isso fica evidente quando esses autores afirmam:

Durante o processo de benchmarking pôde-se observar que algumas empresas juniores, principalmente as empresas direcionadas às áreas de marketing e publicidade, utilizavam, por exemplo, uma departamentalização matricial enquanto outras, voltadas basicamente à atividade de consultoria empresarial, utilizavam uma departamentalização funcional ou por projetos. Além disso, foi possível observar 0 desenvolvimento dos projetos, ou seja, o processo de análise de viabilidade, precificação, realização das etapas e finalização (GRAÇA; PAIS, 2003, p. 6). 
Entende-se que esses passos são relativamente comuns em todos os tipos de EJ brasileiras, com pequenas modificações de acordo com as características do curso de que fazem parte.

Para agregar um melhor entendimento à fundamentação teórica, abaixo segue o modelo de análise que serve de norteador do presente estudo, trazendo uma visão geral do que será apresentado nos capítulos subseqüentes, ao relacionar o que foi fundamentado pela teoria existente no campo de estudo investigado.

\section{Metodologia da pesquisa}

Levando-se em consideração as diferentes formas metodológicas existentes na literatura, classifica-se esta pesquisa como de natureza descritiva e exploratória, envolvendo os alunos participantes de EJ do Brasil e seu comportamento informacional.

Os estudos exploratórios são adequados para pesquisas que querem conhecer e saber mais sobre determinado assunto, ou seja, esclarecer certos aspectos do fenômeno estudado, conforme Quivy e Campenhoudt (1992).

Como procedimento técnico da pesquisa, foi feito um levantamento de dados (survey), mais especificamente um levantamento por meio da internet (websurvey), com o intuito de garantir um índice adequado de retorno dos questionários. A utilização de um programa, cujo acesso é pela internet, contribui para a agilidade do processo, tanto para o pesquisador quanto para os respondentes. Segundo Couper, Traugott e Lamias (2001), os websurvey estão se proliferando rapidamente e facilitam a coleta de dados para qualquer pesquisa exploratória.

A pesquisa sobre o estudo do comportamento informacional dos alunos participantes das EJ do Brasil se propõe utilizando-se da Confederação Brasileira das Empresas Juniores - Brasil Júnior como parceira, distribuidora e incentivadora, para que os questionários sejam respondidos pelos participantes das EJ filiadas. Sabe-se que a Brasil Júnior tem filiadas 140 EJ, que compõem a sua Assembléia Geral, distribuídas por 12 Federações Estaduais. O número de alunos participantes por EJ é variável, mas estima-se um número médio de 25 alunos, perfazendo um universo de aproximadamente 3.500 indivíduos.

Levando-se em conta que foram enviados 460 e-mails-convites para os alunos participantes, o retorno foi positivo, pois se trabalhou com uma amostragem estratificada desses possíveis respondentes, conseguindo-se um número de 270 questionários respondidos.

A unidade de observação desse estudo é o aluno participante das EJ, filiadas ou não à Brasil Júnior, devido ao auxílio que a confederação em questão proporciona, no sentido de avalizar a pesquisa e incentivar os respondentes do questionário. O e-mail-convite foi enviado via Brasil Júnior para todos os e-mails cadastrados. Houve um primeiro encaminhamento pela Brasil Júnior e acreditava-se que fosse uma tentativa de mobilizar os potenciais respondentes com relação à importância de se responder o questionário. 
Em função do baixo retorno inicial por parte dos potenciais respondentes, em contato por telefone com a Brasil Júnior e com a FEJEMG, o pesquisador dividiu os envios para aperfeiçoar e organizar melhor o retorno dos respondentes. Em uma primeira pesquisa no Google com o verbete "empresa júnior", foram coletados alguns websites de EJ que estavam entre os primeiros lugares dentre as ocorrências apresentadas pela ferramenta de busca. Em um segundo momento, necessitou-se de maior aprofundamento da busca para garantir um número maior de contatos nos websites das EJ presentes na web.

Em seguida, o pesquisador enviou pelo sistema de gestão de levantamento de dados Makesurvey, em seu mailing list, três blocos de endereços de e-mail. O primeiro bloco continha 116 endereços, o segundo 226 e o terceiro constava com 118 endereços, totalizando 460 e-mails pessoais e de contato das EJ coletados.

Abaixo, na FIG. 1, é apresentado o esquema, em formato de fluxograma, dos procedimentos de coleta utilizados. Ele representa a divisão dos procedimentos em duas etapas, em função da dificuldade de realização do primeiro, e indica o segundo como a opção mais eficiente do processo de coleta de dados. 
Procedimento 1

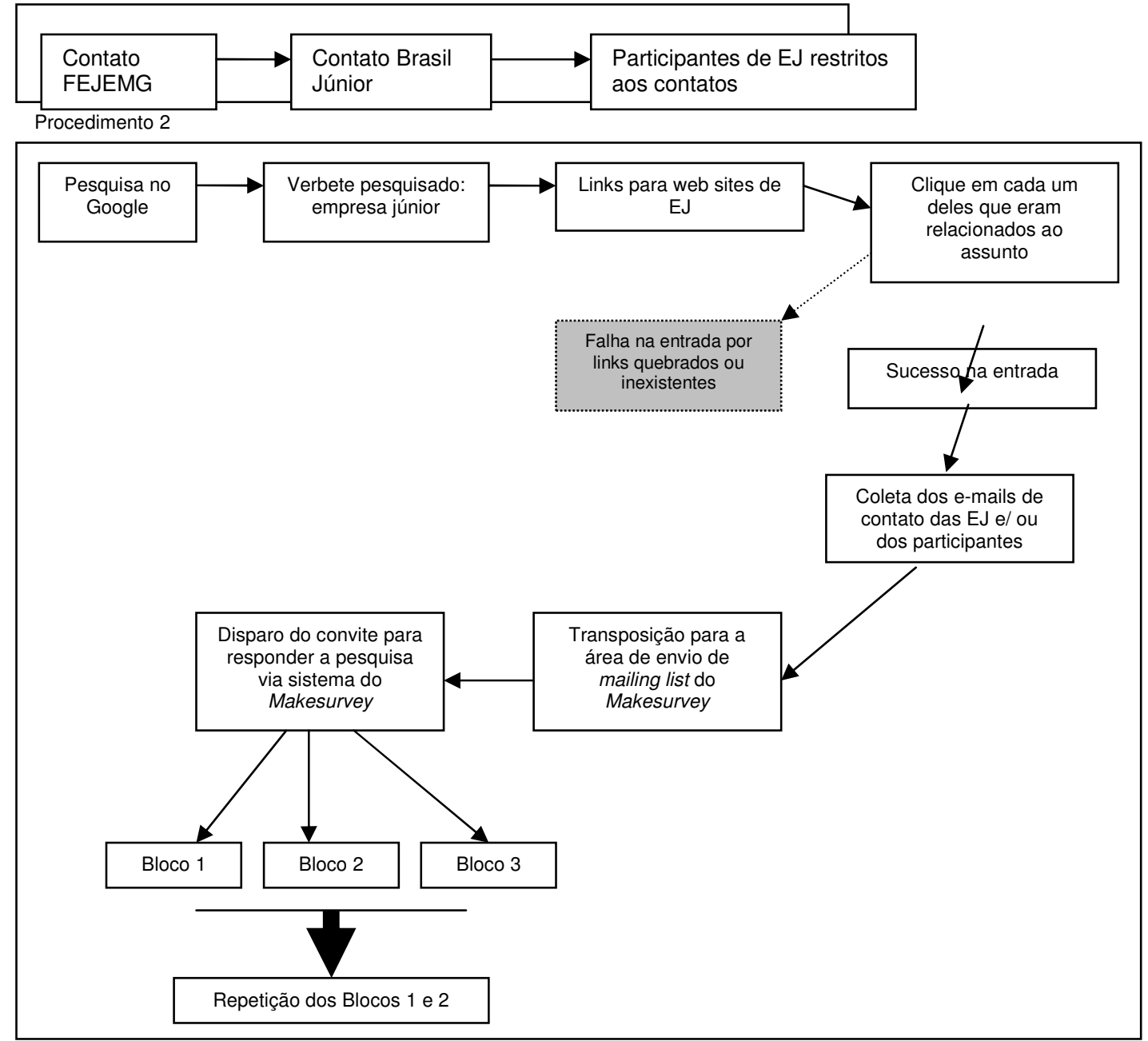

FIGURA 1 - Fluxogramas de procedimentos para coleta de dados

Fonte: Dados da pesquisa.

Para a construção do instrumento de coleta de dados, se viu necessária a técnica de observação participante (DUARTE; BARROS, 2005). O pesquisador do referido estudo fez parte de uma EJ como tutor, portanto, estava inserido no meio a ser pesquisado. A partir de sua vivência e do compartilhamento do espaço de observação, ele fez anotações dos processos e das tarefas executadas e em execução para obter subsídios para a construção dos questionários utilizados na pesquisa. Através desse método, buscou-se estabelecer categorias de análise a serem utilizadas como norteadoras do desenvolvimento do questionário.

A observação participante colaborou para a construção do questionário que, primeiramente, passou por um pré-teste impresso, sendo distribuído e o seu preenchimento acompanhado pelo pesquisador. Foram escolhidos oito alunos participantes da EJ em que o pesquisador atuou como tutor e orientador. Durante o pré-teste, verificou-se que 
alguns dos respondentes tiveram dificuldades em responder algumas perguntas, o que levou a uma melhora e reformulação no conteúdo e na forma de redigir e apresentar a questão.

A base da coleta de dados da pesquisa é o método survey, que, segundo Babbie (1999), é lógico, determinístico, generalista, parcimonioso e específico, atributos que o garantem como sendo "empiricamente verificável".

Como se investigaram os alunos que fazem parte das EJ disseminadas pelo Brasil, os objetivos da Survey como descrição, explicação e exploração são adequados. Especificamente, para se conseguir uma resposta sobre o comportamento informacional, deve haver uma descrição minuciosa de acordo com certos traços e atributos (BABBIE, 1999) verificados. Um objetivo complementar é a explicação com a análise multivariada, ou seja, o cruzamento de variáveis. A exploração é um mecanismo de busca que deve ser utilizado para se melhorar a pesquisa survey, contribuindo para uma análise mais criteriosa dos dados.

O desenho da pesquisa de survey proposto é o estudo contextual, pois através das respostas dos participantes se obtém um panorama geral do ambiente onde estão inseridos.

É um desenho que se adapta ao objeto a ser estudado, por se entender que o contexto ou o ambiente onde os alunos participantes de EJ estão indica o seu comportamento. Aponta também, em certa medida, que suas atitudes ou comportamentos, especificamente os relacionados à informação, determinam o tipo de ambiente propício ou não à coleta, disseminação e uso da informação.

Para garantir uma boa distribuição da pesquisa foram aplicados questionários via web (websurvey), pois se observa que é a melhor maneira de garantir um retorno satisfatório com baixo custo. "É uma forma de levantamento de dados que está se proliferando rapidamente" (COUPER; TRAUGOTT; LAMIAS, 2001, p. 250).

Além disso, ainda de acordo com Couper, Traugott e Lamias (2001), os questionários websurvey são visualmente mais atrativos e contêm mais estímulos para que o respondente se interesse em preencher os campos. O retorno é em tempo real e, se houver algum problema, a correção da trajetória e do desenho da pesquisa é rápida.

Outra justificativa que reforça a disponibilização dos questionários por intermédio da web está na não-dependência de um indivíduo com treinamento para a aplicação. Em muitos casos, a coleta de dados é prejudicada por falha do entrevistador, por falta de empatia ou de interesse.

O instrumento de coleta foi integralmente desenvolvido no ambiente $w e b$ e disponibilizado aos respondentes em um endereço on-line específico (URL), cujo endereço na web é http://www.makesurvey.net. É um sistema cujo objetivo principal é o gerenciamento do levantamento de dados.

Para iniciar o processo, o pesquisador deve se cadastrar e configurar a sua área conforme o tipo de pesquisa, de questões e de forma de 
visualização do questionário. Cada questão deve ser inserida separadamente, podendo ser alterada a conforme necessidade do pesquisador.

Após o cadastramento no website e a inserção de todas as questões a serem levantadas, o pesquisador enviou uma mensagem, convidando os alunos participantes das EJ a responderem à pesquisa.

\section{Resultados}

\subsection{Perfil do respondente}

Através do levantamento de dados feito pelo questionário aplicado via websurvey, determinou-se o perfil dos alunos participantes das EJ, conforme questões como: gênero, faixa etária, nome da universidade/faculdade em que estuda, curso, tempo de EJ, papel desempenhado na EJ e tempo de dedicação diário à EJ. Para tal, algumas tabelas foram organizadas para se visualizar e compreender a composição da população respondente.

Observa-se que 59\% dos entrevistados são do sexo masculino e, portanto, $41 \%$ são mulheres. Em relação à idade dos respondentes, houve uma maior concentração na faixa de 19 a 21 anos (62\%) e entre 22 a 25 anos $(26 \%)$. O maior número de respondentes veio da Universidade Federal de Santa Catarina, com 27 entrevistados, seguido da Universidade Federal da Bahia, que totalizou 24. Outras instituições que se destacaram foram as Federais do Rio Grande do Sul, do Rio de Janeiro e do Paraná, com 22, 19 e 18, respectivamente. As demais instituições que apresentaram bom número de respondentes foram a USP - Universidade de São Paulo e a Universidade Estadual do Rio Grande do Sul, com 17 respondentes cada.

A região com o maior número de respondentes é a Sudeste, com $42 \%$, acompanhada de perto pela região Sul, de onde vieram $39 \%$ dos alunos que foram entrevistados e participam de EJ. O Nordeste obteve $15 \%$ dos respondentes. Somente $4 \%$ são do Centro-Oeste, representado por alunos da UnB (Universidade de Brasília). De acordo com o levantamento feito, o curso que obteve a maioria de respondentes foi o de Administração (71), em seguida o curso de Ciência da Computação (27), o de Ciências Econômicas (24) e o de Engenharia Elétrica (23). Mas, somando-se todos os alunos dos cursos de Engenharia, obtém-se quase um terço dos respondentes (30\%).

Observa-se que 24\% dos respondentes está há 2 semestres ou 1 ano na EJ, mas destaca-se que $19 \%$ trabalham na EJ há mais de 4 semestres, ou seja, dedicam-se às atividades na EJ por mais de 2 anos. Em relação ao principal papel desempenhado na EJ onde trabalha, a maioria respondeu que sua função é de Liderança (32\%), logo após os alunos autodenominaram-se Organizadores (23\%) e, em seguida, mostraram-se como os responsáveis pela Produção ou Execução de trabalhos/ projetos (20\%). 
Os dados sobre o tempo despendido na EJ mostram que $26 \%$ dos alunos que responderam ao questionário passam mais de 4 horas dedicados à EJ, diariamente. Próximos deste número estão aqueles que dedicam 2 horas diárias (24\%) às atividades da EJ. Foi observado, também, que um grande percentual de respondentes $(80 \%)$ passa acima de 2 horas com dedicação à EJ.

\subsection{Comportamento de busca pelas fontes de informação}

Observou-se, nos resultados apresentados pela pesquisa, que as fontes de informação mais buscadas são as formais e formais e internas, representadas pelas conversas com colegas e troca de e-mail com colegas, em virtude da facilidade de acesso por parte dos alunos participantes de EJ. As fontes eletrônicas, procura em sites de busca e conversa via Messenger, também tiveram boa freqüência de busca. Ao contrário, as fontes de informação que obtiveram menos freqüência de busca foram as formais, sejam eletrônicas ou não-eletrônicas, como a troca de e-mails com os professores e a conversa com os professores.

Assim como no resultado anteriormente apresentado, os alunos participantes indicaram que as fontes mais relevantes são as pessoais, internas e eletrônicas, que são os contatos via e-mail com os colegas; mas o grande destaque ficou para a conversa com os colegas, visto que $100 \%$ dos respondentes indicaram elevado grau de relevância à fonte.

O resultado apresenta a grande importância que os alunos participantes de EJ dão às fontes informais. Observa-se, entretanto, que a leitura de livros da área (fonte impessoal) e as conversas com os professores (fonte formal e pessoal) são fontes de informação bastante importantes, com 83\% considerando "extremamente relevantes" e "relevantes" o seu acesso; são também consideradas muito relevantes as palestras e debates na área (82\%). Os dados indicaram que o acesso a informações restritas no site da faculdade/universidade (intranet ou extranet) é o considerado de menor relevância para os alunos participantes de EJ, com $18 \%$ tendo respondido como "irrelevante" e "totalmente irrelevante". Em seguida, a leitura de e-mails recebidos após cadastro (newsletter, e-mail marketing), fonte de informação que obteve baixa relevância, com $15 \%$ dos respondentes. Observam-se esses dados devido ao fato de essas fontes serem altamente formais, exigirem maior esforço e apresentarem dificuldade de acesso.

Em relação à confiabilidade ao buscar as fontes de informação determinadas, os resultados mostram que os livros da área (fonte formal, impessoal e não-eletrônica) são os mais confiáveis para os alunos participantes de EJ. Depois, o destaque está nas conversas com os professores (fonte formal, pessoal e não-eletrônica), em que 34\% dos respondentes indicaram o grau de "extremamente confiável" e 43\% marcaram como "confiável".

O que se observou nos resultados é que as conversas por mensagens instantâneas são as menos confiáveis pelos participantes. Um 
terço deles, aproximadamente, considera tal conversa pouco ou nem um pouco confiável. Vê-se também que as fontes informais e pessoais são as com maior freqüência, porém são as menos confiáveis na opinião dos alunos participantes de EJ. As conversas com os professores também estão entre as menos confiáveis, com $20 \%$ das respostas indicando pouco ou nem um pouco confiáveis; observando-se que, apesar desse resultado, os alunos participantes acham relevante conversar com os professores. Mas, ao mesmo tempo, é uma das fontes mais confiáveis para eles, entrando na segunda colocação, com a opinião de $34 \%$ dos respondentes.

\subsection{Comportamento de uso através das fontes de informação}

Com base nas 14 fontes de informação selecionadas, os alunos participantes das EJ responderam a questões referentes à importância e à freqüência com que são usadas para diferentes propósitos como: compartilhar, armazenar, solucionar problemas, desenvolver projetos, atender a clientes e aprender.

Observa-se que as fontes de informação listadas são as mais freqüentemente usadas entre os respondentes, com $87 \%$ "a todo o momento" e "todos os dias" para se adquirir aprendizado. Em seguida, usam-se as fontes de informação com mais frequência para compartilhamento, pois $81 \%$ responderam que a usam "a todo o momento" e "todos os dias". Também são usadas as fontes de informação para solucionar problemas em $64 \%$ dos casos "a todo o momento" e "todos os dias".

Visualizou-se, de forma geral, que os alunos demonstraram, através de suas respostas, que dão importância a todos os tipos de uso das fontes de informação, mas destaca-se como "muito importante" e "importante", para eles, o aprendizado, com $100 \%$ dos respondentes. O compartilhamento (99\%) e a solução de problemas (99\%) também obtiveram números expressivos de respondentes que os consideram importantes.

\section{Conclusão}

Para se poder conhecer e analisar o comportamento informacional, é fundamental conhecer a quem essa informação é direcionada. Portanto, a partir das necessidades informacionais, das buscas por fontes de informação, de como os usuários da informação as usam e com qual objetivo é que se pode conhecer o seu comportamento informacional.

Os empresários juniores, aqui estudados e chamados de alunos participantes de EJ, são os futuros empreendedores. Isto ocorre por já se envolverem desde os seus cursos de graduação com uma organização empresarial, mas também por transmitirem aos novos alunos participantes o espírito empreendedor.

$\mathrm{Na}$ presente pesquisa com os alunos participantes de empresas juniores, e tendo como base os objetivos propostos de pesquisa, pode-se 
afirmar que 0 estudo sobre as práticas informacionais, mais especificamente o comportamento informacional dos alunos participantes de EJ no Brasil, apresentou dados significativos. Os resultados para o campo do comportamento informacional são de suma importância, mas também podem contribuir de maneira efetiva para o crescimento e a evolução do movimento EJ em âmbito nacional.

Acredita-se que estes resultados obtidos contribuíram para que as entidades federadas à Brasil Júnior possam direcionar seus esforços, no sentido de suprir as necessidades evidenciadas pelo comportamento informacional de seus afiliados.

Os resultados alcançados com essa pesquisa e a metodologia aplicada sugerem uma série de possibilidades para novos estudos. O fato de que essa pesquisa tenha sido realizada com dados quantitativos já abre precedentes para que haja um novo estudo, mais aprofundado, trabalhando-se com os métodos quantitativos. $O$ que se pode desenvolver é uma entrevista em profundidade com um grupo de alunos participantes, para se identificar mais fontes de informação.

Em outra perspectiva, mais dimensões oriundas dessa mesma pesquisa podem ser investigadas pelo cruzamento estatístico de dados como, por exemplo, a relação entre a idade dos entrevistados e a freqüência com que buscam determinada fonte de informação. Ainda, podem-se cruzar os dados de gênero com a importância que dão a uma ou outra fonte de informação. Pode-se também fazer cruzamentos de dados quantitativos entre os respondentes que consideram as fontes mais relevantes e confiáveis e sua freqüência de uso para determinado objetivo. Ou mesmo cruzar as variáveis tempo de atividades na EJ e grau de confiança nas fontes de informação mais acessadas.

O presente estudo pode contribuir para a evolução dos estudos em ambientes organizacionais poucos pesquisados, como é o caso das EJ. Esse ambiente é uma ligação entre a academia e o mercado de trabalho, ou seja, um ambiente peculiar, que demanda comportamentos informacionais de indivíduos em um contexto informacional característico, com acesso a fontes de informação diferenciadas.

O comportamento de busca e uso da informação, ainda em evolução, amplia um pouco mais suas perspectivas com essa pesquisa, pois traz à tona a realidade dos alunos das universidades brasileiras, diante das formas com que acessam as informações e de como as usam para construir conhecimento, seja pelo aprendizado, pelo compartilhamento, ou mesmo para solucionar problemas.

\section{Referências}

AUSTER, E.; CHOO, C. W. Environmental Scanning: acquisition and use of information by managers. Annual Review of Information Science and Technology, vol. 28, p. 279-314, 1993. 
- CEOs, information, and decision-making: scanning the environment for strategic advantage, Library Trends, v. 43, n. 2, p. 206225, Fall 1994.

BABBIE, E. Métodos de pesquisa de survey. Belo Horizonte: Editora UFMG, 1999.

BARBOSA, R. R. Acesso e necessidades de informação de profissionais brasileiros: um estudo exploratório. Perspect. cienc. inf., Belo Horizonte, v. 2, n. 1, p. 5 - 35, jan./jun. 1997.

. Inteligência empresarial: uma avaliação de fontes de informação sobre o ambiente organizacional externo. DataGramaZero - Revista de Ciência da Informação, Rio de Janeiro, v. 3, n. 6, dez. 2002.

. Uso de fontes de informação para a inteligência competitiva: um estudo da influência do porte das empresas sobre o comportamento informacional. R. Eletr. Bibliotecon. Ci. Inf, Florianópolis, n. esp., $1^{0} \mathrm{sem}$. 2006.

BASTOS, J. S. Y.; BARBOSA, R. R. O uso de fontes de informação por executivos do setor de tecnologia da informação. In: ENCONTRO NACIONAL DE PESQUISA EM CIÊNCIA DA INFORMAÇÃO (ENANCIB), 6., 2005, Florianópolis, Anais... Florianópolis: ANCIB, 2005.

BLAIS, R. A. (Ed.). Creating innovative companies through spin-offs. In: TECHNOLOGICAL Entrepreneurship and Engineering in Canada. Ottawa: The Canadian Academy of Engineering, 1997.

BRASIL JÚNIOR - CONFEDERAÇÃO BRASILEIRA DE EMPRESAS JUNIORES. Conceito Nacional de Empresa Júnior. Salvador: [s. n.], 2006. Disponível em: <http://uaua.ufba.br/brasiljr/>. Acesso em: 26 set. 2006.

BURKE, Ronald J. Information sources and their usefulness in a professional services organization. Management Decision, v. 34, n. 1, p. 60-65, 1996.

- Information sources: is there a gender issue? Corporate Communications: An International Journal, v. 6, n. 1, p. 7-11, 2001.

CASE, D. O. Looking for Information: a survey research on information seeking, needs, and behavior. San Diego, CA: Academic Press - Elsevier, 2002.

CHOO, C. W. A organização do conhecimento: como as organizações usam a informação para criar significado, construir conhecimento e tomar decisões. São Paulo: Senac, 2003.

. The Knowing Organization: how organizations use information to construct meaning, create knowledge, and make decisions. New York: Oxford, 2006. 
$\mathrm{CHOO}, \mathrm{C} . \mathrm{W}$. Perception and use of information sources in environmental scanning. Library \& Information Science Research, v.16, n.1, p.23-40, 1994.

CHOO, C. W.; DETLOR, B.; TURNBULL, D. Information seeking on the web: an integrated model of browsing and searching. First Monday, v. 5, n. 2, Feb. 2000.2 Disponível em: < http://firstmonday.org/issues/issue5 2/choo/index.html>. Acesso em: 21 abr. 2008.

COUPER, M. P.; TRAUGOTT, M. W.; LAMIAS, M. J. Web Survey Design and Administration. Public Opinion Quaterly, v. 65, p. 230-253, 2001.

DAVID, D. E. H. Intraempreendedorismo social: perspectivas para o desenvolvimento social nas organizações. 2004. Tese (Doutorado em Engenharia de Produção e Sistemas) - Universidade Federal de Santa Catarina, Florianópolis, 2004.

DERVIN, B., NILAN, M. Information needs and uses. In: WILLIAMS, M. E. (Ed.) Annual review of information science and technology. White Plains, NY: Knowledge Industries, 1986. v.21, p. 3-33.

DUARTE, J.; BARROS, A. (Orgs.). Métodos e técnicas de pesquisa em comunicação. São Paulo: Atlas, 2005.

ELLIS, D. A. A behavioral model for information retrieval system design. Journal of Information Science, Cambridge, n. 15, p. 237-247, 1989.

ELLIS, D. A.; COX, D.; HALL, K. A comparison of the information seeking patterns of researchers in the physical and social sciences. Journal of Documentation, London, v. 49, n. 4, p. 356-369, 1993.

FARLEX INC. The Free Dictionary by Farlex. Dezembro de 2004. Disponível em: <http://www.thefreedictionary.com>. Acesso em: 27 set. 2008.

FILION, L. J. Empreendedorismo: empreendedores e proprietáriosgerentes de pequenos negócios. Revista de Administração, São Paulo, v. 34, n. 2, p. 5-28, abr./jun., 1999.

GRAÇA, M. S.; PAIS, S. B. Um espaço para a experiência prática no ensino de graduação: O caso da criação da Qualitas, a empresa júnior da Facamp. In: SEMINÁRIOS EM ADMINISTRAÇÃO (SEMEAD), 4., São Paulo, 2003. Anais... São Paulo: USP, 2003. Disponível em: $<$ http://www.ead.fea.usp.br/semead/6semead/ENSINO/021ENS\%20\%20Um\%20Espa\%E70\%20para\%20a\%20Experi\%EAncia\%20pr\%E1tica.doc.>. Acesso em: 12 jul. 2007.

HARPER, D. Online Etymology Dictionary. November 2001. Disponível em: $<$ http://www.etymonline.com>. Acesso em: 27 set. 2008. 
KUHLTHAU, C. C. Inside the search process: Information seeking from the user's perspective. Journal of the American Society for Information Science, v. 42, n. 5, p. 361-371, 1991.

LEÃO, I. Empresas juniores: criativas e crescendo cada vez mais. Jornal da USP, v. 12, n. 411, 1997. Disponível em: <http://www.usp.br/jorusp/arquivo/1997/jusp411/manchet/rep res/rep int/univers3.ht $\underline{\mathrm{ml}}>$. Acesso em: 26 set. 2006

LEMOS, P.; GRIZENDI, E.; LOTUFO, R. Empreendedorismo, empresas juniores e cadeia de inovação: a experiência de pré-incubação da INOVA/UNICAMP. In: SEMINÁRIO NACIONAL DE PARQUES TECNOLÓGICOS E INCUBADORAS DE EMPRESAS, 15., 2005, Curitiba. Seminário Nacional de Parques Tecnológicos e Incubadoras de Empresas. Brasília: ANPROTEC, 2005.

NORMAN, O. G. The Impact of Electronic Information Sources on Collection Development: a Survey of Current Practice. Library Hi Tech, v. 15, n. 57-58, p. 123-132, 1997.

PEREIRA, F. C. M. Uso de fontes de informação: um estudo em micros e pequenas empresas de consultoria de Belo Horizonte. 2006. Dissertação (Mestrado em Ciência da Informação) - Escola de Ciência da Informação, Universidade Federal de Minas Gerais. Belo Horizonte, 2006.

QUIVY R.; CAMPENHOUDT, L. V. Manual de investigação em ciências sociais. Lisboa: Gradiva, 1992.

SOUZA, G. C. Empresa Júnior: uma ferramenta facilitadora do processo de aprendizagem através da aplicação imediata de conceitos e teorias à realidade empresarial no ensino de administração no Brasil. Revista ANGRAD, Rio de Janeiro: Associação Nacional dos Cursos de Graduação em Administração, v. 3, n. 4, p. 98-111, out/dez. 2002.

TAYLOR, R. S. Information use environments. In: DERVIN, B.; VOIGT, M. (Eds.). Progress in communication science. Norwich, NJ: Ablex, 1991. p. 173216

TOMAÉL, M. I. et al. Avaliação de Fontes de Informação na Internet: critérios de qualidade. Informação \& Sociedade: estudos, João Pessoa, v. 11 , n. 2, p. 13-35, 2001.

WILSON, T. D. Models in Information Behavior Research. Journal of Documentation, v. 55, n. 3, p. 249-270, 1999.

Exploring models of information behaviour: the 'uncertainty' project. Information Processing and Management, v. 35, p. 839-849, 1999.

Human Information Behavior. Information Science

Research, v. 3, n. 2, p. 49-55, 2000. 